\title{
Psicologia e liberdade: CONHECIMENTO DO "EU" E DAS COISAS
}

Leonardo Almada ${ }^{\star}$

\section{RESUMO}

Nesse artigo, proponho investigar a significação do problema da liberdade no âmbito de um debate entre a tradição espiritualista e a psicologia experimental. Meu objetivo é o de demonstrar que a conceituação da mente como duração nãoespacializada e como multiplicidade qualitativa é capaz de suprir os empecilhos à liberdade que são instituídos pela psicologia experimental. Para tanto, recorro às obras dos filósofos Henri Bergson e Farias Brito, no tanto quanto souberam expressar e se posicionar em face dos propósitos experimentalistas. A conclusão obtida é a de que a causalidade não é determinação e, por isso, não exclui a liberdade.

Palavras-chave: liberdade; duração; tempo e espaço; multiplicidade; psicofisica.

\section{Psychology ANd FREedom: KNOWLEDGE OF SELF AND THINGS}

\begin{abstract}
In this paper, my aim is to investigate the significance of the problem of freedom in the context of the discussion between spiritualist tradition and experimental psychology. My goal is to demonstrate that the concept of mind as duration nonspatialized and as qualitative multiplicity is capable of supplying the obstacles to freedom that are established by experimental psychology. Therefore, I turn to the works of Henri Bergson and Farias Brito, in so far as recognized and positioned themselves in the face of the experimentalists' purposes. The conclusion is that causality is not determination and therefore does not exclude freedom.
\end{abstract}

Keywords: freedom; duration; time and space; multiplicity; psychophysics.

\footnotetext{
^ Doutor e Mestre em Filosofia pelo Programa de Pós-Graduação em Filosofia da Universidade Federal do Rio de Janeiro. Professor Efetivo Adjunto I (Dedicação Exclusiva) da Faculdade de Filosofia da Universidade Federal de Goiás (FAFIL-UFG) e Membro Permanente do Programa de Pós-Graduação em Filosofia (Mestrado) da Universidade Federal de Goiás. Endereço: Universidade Federal de Goiás, Faculdade de Ciências Humanas e Filosofia, Faculdade de Filosofia. Campus II (Samambaia). Goiania, GO - Brasil. CEP: 74001-970. Caixa-Postal: 131.

E-mail: leonardo.f.almada@gmail.com
} 


\section{A presentaÇão do PROBlema}

Sob a influência da atitude teórica de Tobias Barreto, Farias Brito iniciou sua obra filosófica pelo exame crítico das teses do então famoso mestre do Recife. De tal empreitada resultou Finalidade do mundo (1957[1905]), que o levou a defender a necessidade de uma nova ciência do espírito, que fosse capaz de dar conta do sujeito "psicológico", como a psicologia "científica" ou "experimental", mas também de fundamentar uma nova teoria da experiência,

[...] determinando com absoluta precisão todas as energias [...] e todas as possibilidades, quer de ação, quer de fato, quer de pensamento, quer de realidade, que se encerrem nestas energias, de maneira que nada aí exista que não fique conhecido de modo completo, absoluto, [o que] seria explicar a totalidade das coisas (BRITO, 2003b[1914], p. 257).

Por outro lado, Farias Brito, sem jamais ter feito referência a Gonçalves de Magalhães, manteve-se em sua mesma perspectiva metodológica, sobretudo no que concerne a uma compreensão da realidade das coisas, do mundo e da vida sob o âmbito da consciência, e mediante o método psicológico.

De pleno acordo com Tobias quanto à rejeição do método natural para dar conta das ciências humanas, o que mais claramente identifica o pensamento de Farias Brito é a ideia de espírito enquanto energia viva e criadora, cuja essência o situa, enquanto tal, para além dos alcances e limites inerentes aos meros movimentos externos dos corpos que se deslocam no espaço. É nesse mesmo sentido que Farias Brito justifica a vinculação a qual estabelece com o filósofo francês Henri Bergson. É desta fonte que assimila a tese de que incorremos em absurdo quanto procuramos para a realidade do psíquico um equivalente mecânico, interpretando-a, assim, "pela mesma forma que a realidade exterior, pelo peso e pela medida, pela agregação e pela desagregação da matéria" (BRITO, 2003a[1914], p. 52).

Com efeito, é sob a força dessa influência que Farias Brito, inserindo-se na perspectiva de Kant, enuncia que "não basta indagar se o conhecimento das coisas depende da constituição de nosso espírito" (BRITO, 2003a[1914], p. 220). E é exatamente em franca e declarada consonância com a posição de Bergson quanto à necessidade de ultrapassar o sentido de idealidade e subjetividade do espaço e do tempo que Farias Brito se apoia em sua sugestão de estabelecer a questão real nos seguintes termos: "é preciso verificar se o conhecimento do eu e da consciência, por sua vez, não sofre a influência das coisas" (BRITO, 2003a[1914], p. 220). Com efeito, tal inversão é decisiva na medida em que é a partir da influência do conhecimento das coisas no conhecimento do "eu" que se segue a postura de conceber o espírito se desenvolvendo no espaço, quando, na verdade, é da natureza do objeto das ciências naturais, isto é, da matéria, desenvolver-se no espaço. Daí ser natural, por sua vez, a tentativa de compreensão do espírito consoante as operações constitutivas da matéria, bem como é daí, igualmente, "a tendência para explicar a intensidade pela extensão, a qualidade pela quantidade, a liberdade pela necessidade" (BRITO, 2003a[1914], p. 221). 
[A dificuldade é porque] experimentamos uma incrível dificuldade em representar a duração na sua pureza original; e, sem dúvida, isto se deve a que não duramos sozinhos. [Com efeito, na medida em que parece que as] coisas exteriores duram como nós, [segue-se que o tempo, considerado sob esse último ponto de vista], tem todo o aspecto de um meio homogêneo, [quando, na verdade, a homogeneidade é da natureza do espaço, e não do tempo, como equivocamente pretendia Kant] (BERGSON, 1988[1889], p. 64-65).

A confusão, portanto, reside no fato de que a psicofísica não dissocia as duas espécies de multiplicidades, a saber: "a dos objetos materiais, que forma um número imediatamente, e a dos fatos de consciência, que não podem adquirir o aspecto de um número sem intermediário de alguma representação simbólica" (BERGSON, 1988[1889], p. 65), o que implica, com efeito, a intrusão da ideia de espaço na ideia de consciência e, por extensão, o equívoco conceitual. De pleno acordo com Bergson, diz Farias Brito que "para estudar o eu em sua pureza original, é indispensável considerá-lo em si mesmo, em sua significação própria, isolados os seus elementos e feita a eliminação de certas formas que reveste, originadas diretamente do mundo exterior" (BRITO, 2003a[1914], p. 221).

\section{TEMPO E ESPAÇO NA MENTE: CONSCIÊNCIA COMO DURAÇÃo}

Ora, para que compreendamos o sentido desta questão e da subsequente vinculação entre as posições de Farias Brito e de Bergson, mais precisamente a expressa em Ensaios sobre os dados imediatos da consciência, ${ }^{1}$ é preciso que atentemos para o momento em que o expoente do espiritualismo francês traça uma relação entre um "eu interior" e um "eu fenomênico e mundano", visando a situar a gênese dos equívocos sobre os quais a modernidade se estabeleceu e dos prejuízos que se seguiram daí. Os prejuízos decorrentes da psicologia moderna, com efeito, derivam do fato de que o método matemático-experimental, em função de sua própria natureza, é equívoco na mesma medida em que não pode levar em consideração o "eu interior", um eu mais profundo que é aquele "o que sente e se apaixona, o que delibera e se decide [enquanto] força cujos estados e modificações se penetram intimamente" (BERGSON, 1988[1889], p. 88). Em contrapartida, o eu fenomênico e mundano é o eu superficial, resultante do fato de que "o nosso eu toca no mundo exterior superficialmente; as nossas sensações sucessivas, embora se apoiando umas nas outras, conservam algo da exterioridade recíproca que caracteriza objetivamente as suas causas" (BERGSON, 1988[1889], p. 88). Nesse sentido, a confusão inerente à visão da psicologia moderna consiste em supor que o "eu interior" e o "eu fenomênico" duram da mesma maneira, o que configura, decerto, um reflexo do fato de que esse eu mais profundo "não faz senão uma única e mesma pessoa com o eu superficial" (BERGSON, 1988[1889], p. 88). O que ocorre, na verdade, é o fato de o eu superficial ser facilmente assimilável pelas ciências físicas, pois nossa vida psicológica superficial se desenrola no mesmo meio homogêneo em que se desenrolam os objetos físicos, isto é, no espaço. 
Henri Bergson exerce notável influência sobre Farias Brito, sobretudo a partir da exigência de assumir posição perante os rumos tomados pela filosofia moderna, de onde advogaram a tese de que a filosofia, por sua essência, é a atividade que visa a contemplar a especificidade do psíquico. A filosofia se nos apresenta como um princípio de atividade; a "filosofia é, de fato, a atividade mesma do espírito; é o espírito mesmo elaborando o conhecimento; é o espírito investigando, analisando, estudando e, em consequência dessa investigação, desta análise, deste estudo, produzindo a ciência" (BRITO, 2005 [1905], p. 3). Reside aí o pensamento consoante o qual é inerente à filosofia a busca de um método e de uma orientação, o que a transforma em psicologia. É precisamente esta tarefa o que levou Bergson a reconhecer a necessidade de analisar com maior precisão a possibilidade de analogia entre as realidades do espaço e do tempo, como queria Kant. A questão que levanta, pois, é a seguinte: o fato de o tempo ser concebido sob a forma de um meio homogêneo não será o reflexo de uma intrusão da ideia de espaço no domínio da consciência pura? A assimilação da ideia de tempo como redutível à ideia de espaço é incompatível com a tentativa de construir a representação do espaço com a de duração.

Por um lado, há duas concepções possíveis de duração, sendo que, em uma intervém a ideia do espaço. Este não é o caso da duração (pura) que se refere à consciência, a qual é ausente de qualquer mistura e sem nenhuma relação com a ideia de espaço, tal qual pretendia a psicofísica e seu método de análise dos estados de consciência. No domínio da consciência, portanto, não há separação entre o estado presente e os anteriores, e no seu interior não há justaposição entre eles, mas uma organização, uma penetração mútua entre os estados da consciência. Na consciência, sucessão não é incompatível com a duração, e tampouco há uma relação necessária entre sucessão e distinção, mas antes, é a analogia entre as realidades do tempo e do espaço o que gera o caráter necessário dessa relação. Decerto, é a projeção do tempo no espaço o que torna contraditório o pensamento da sucessão sem distinção, de sorte que, caso se delimite com clareza a realidade do tempo em relação à realidade do espaço, é possível conceber a sucessão sem a distinção, como uma "penetração mútua, uma solidariedade, uma organização íntima de elementos, em que cada um, representativo do todo, dele não se distingue nem se isola a não ser por um pensamento capaz de abstração" (BERGSON, 1988[1889], p. 73). Se, portanto, a interferência da ideia de espaço em nossa representação da sucessão pura é o resultado da tentativa de aplicação do método das ciências naturais no âmbito do psíquico, a psicologia experimental se equivoca na medida em que justapõe os estados de consciência de modo a percepcionálos simultaneamente, não um no outro, mas antes, um ao lado do outro. Assim, confunde-se duração com extensão, e a sucessão é concebida, no sistema dos psicofísicos, como uma linha contínua, ou como uma cadeia cujas partes se tocam sem se penetrar. Tal concepção é decerto contraditória, sobretudo se levarmos em consideração, segundo Bergson, que tal imagem implica a percepção do antes e do depois de modo simultâneo, e não sucessivo, o que exclui a possibilidade de, nesse caso, pensar em sucessão, na medida em que sucessão não se coaduna com um só e mesmo instante. De fato, o pensamento de uma ordem de sucessão na 
duração, isto é, da sucessão pura, não se harmoniza com a mistura da extensão, ou com a sucessão simbolicamente representada em um deslocamento no espaço, na qual não subsiste, ao mesmo tempo, vários termos separados e justapostos. Assim, o que parece justificar, em princípio, a analogia entre as realidades do tempo e do espaço é, na verdade, o fato de que "contamos os momentos sucessivos da duração e que, pelas suas relações com o número, o tempo nos surge, em primeiro lugar, como uma grandeza mensurável, completamente análogo ao espaço" (BERGSON, 1988[1889], p. 75). Todavia, a duração pura proclama que tal analogia é apenas ilusória.

O confronto entre o "eu" profundo e vivo e o "eu" superficial e morto, ou seja, entre o "eu" e sua "sombra", insere-nos em um embate o qual remete a duas realidades que, embora independentes, inerem ao homem: embora não durem da mesma maneira, o "eu" profundo e o "eu" superficial fazem uma só e mesma pessoa. Decerto, é a dificuldade de compreender a conjunção entre a consciência e o organismo sobre o qual opera, e a subsequente tentativa de apreender o psíquico consoante um modo objetivo o que nos insere em uma dificuldade de proporções ainda maiores, a saber: compreender a liberdade como um fato que diz respeito essencialmente à duração, isto é, à consciência. Inserindo-se nessa discussão, Farias Brito reconhece que, "conhecidas as ideias sobre a intensidade e a multiplicidade dos estados psicológicos, sobre o movimento, a consciência e o 'eu', a questão da liberdade torna-se uma questão ociosa". Afinal, "a consciência é a liberdade mesma” (BRITO, 2003a[1914], p. 244). Sem deixar de levar em consideração que na consciência existe um poder indeterminado e de significação puramente subjetiva - uma vez que na consciência tudo se resolve em duração ou pura sucessão resta que não há nenhuma espécie de analogia real entre a consciência e a existência externa que lhe é simultânea, isto é, sua "sombra". Sem negar, ademais, que este poder indeterminado da consciência apresenta suas próprias leis, Farias Brito, apoiando-se novamente em Bergson, reitera a afirmação de que tais leis em tudo superam as leis constituintes do determinismo, do mecanismo.

\section{JUSTAPOSIÇÃO, MULTIPLICIDADE QUALITATIVA E QUANTITATIVA}

Com efeito, a questão da liberdade no homem, ou seja, de uma dinâmica que decorre das leis próprias da consciência, remete-nos invariavelmente ao confronto que se estabelece entre dois sistemas opostos da natureza, no caso, o "mecanicismo" e o "dinamismo". Costumeiramente, o dinamismo representa a atividade voluntária que é fornecida pela consciência, e compreende "sem dificuldade uma força livre, por um lado, e, por outro, uma matéria governada por leis" (BERGSON, 1988[1889], p. 99). É neste sentido que Farias Brito considera, com Bergson, que a ação resulta da consciência exatamente na mesma medida em que o movimento deriva da força, de onde se segue que o movimento originado da força é essencialmente "necessidade" da mesma forma que a ação, o movimento que deriva da consciência, tem por marca axial a "liberdade". A compreensão de que estas dimensões não se misturam nem se excluem não é comparticipada pelo mecanismo. Circunscrevendo-se àqueles materiais de onde depreendem usualmente sua síntese, o mecanicismo supõe que tudo na natureza, 
inclusive a consciência, é regido por leis necessárias: e mesmo atingindo combinações "cada vez mais ricas, cada vez mais difíceis de prever, cada vez mais contingentes aparentemente, não sai do círculo estreito da necessidade em que desde o princípio se encerrava" (BERGSON, 1988[1889], p. 99).

Daí porque o determinismo psicológico se associa à filosofia do associacionismo. Na compreensão de Farias Brito (2003a[1914], p. 244),

[a concepção associacionista faz do "eu"] um agregado de estados exteriores que se distinguem uns dos outros, podendo assim valer uns como causas, outros como efeitos. [Daí a crença de que] os estados de consciência possam ser combinados ou separados, que possam ser justapostos, que se possam enfim sujeitar a operações de síntese ou de análise, como se tratasse de elementos químicos.

A resolução de tais dificuldades depende do esclarecimento quanto à distinção entre multiplicidade da justaposição e multiplicidade de fusão ou de penetração mútua. $\mathrm{O}$ associacionismo concebe os sentimentos e as ideias a partir de uma pluralidade indefinida de fatos de consciência, cuja aparição só se realiza "em uma espécie de desdobramento no meio homogêneo que alguns chamam duração e que, na realidade, é espaço" (BERGSON, 1988[1889], p. 116). O equívoco do associacionismo, destarte, consiste em reduzir os fatos da consciência cuja multiplicidade é a de fusão e de penetração mútua - a seus símbolos, isto é, às palavras que os exprimem, o que engendra a redução dos estados de consciência a termos exteriores uns aos outros, sob o paradigma da multiplicidade da justaposição. $\mathrm{O}$ associacionismo segue a interpretação mais comum, no caso, a de equiparar nossa razão com a ideia de espaço e com o poder de criar símbolos, assim suplantando o fenômeno concreto - que ocorre no espírito - em vista de uma reconstituição artificial. $\mathrm{O}$ associacionismo se baseia em um fato real, a saber: "o 'eu' toca no mundo exterior pela sua superfície; e como esta superfície conserva a marca das coisas, associará por contiguidade termos que percepcionara justapostos" (BERGSON, 1988[1889], p. 115).

Quando, porém, adentramos na consciência, isto é, à medida que o "eu" se volta para si mesmo, os seus estados de consciência não se justificam mais em justaposição, mas apresentam-se em sua íntima e recíproca penetração, fundindose e colorindo-se em função da cor de todos os outros. Trata-se daquilo que Farias Brito (2003a[1914], p. 243) pensara quando afirmou que, "pela organização dos estados psicológicos, uma realidade se constitui, que é inteiramente distinta da realidade exterior; que não ocupa espaço, se bem que tenha por destino próprio agir sobre as coisas no espaço". É nesse sentido que o "eu" toca no mundo exterior pela superfície, isto é, na medida em que seu destino próprio consiste em agir sobre as coisas no espaço. E é no mesmo sentido de Bergson que Farias Brito (2003a[1914], p. 244) considera a existência própria do "eu" como sui generis e particular, realizada "por fusão e penetração dos estados psicológicos, não por justaposição, e de onde, por isto mesmo, é em absoluto excluída toda a multiplicidade numérica". Tal compreensão leva Farias Brito a reiterar a ideia bergsonia- 
na de "eu" como "heterogeneidade puramente qualitativa" sem "extensão" nem "quantidade", de onde retira a ideia de que uma "ciência do espírito' deve ter em conta a mônada impalpável, ativa e pensante, o átomo inextenso, princípio mesmo de ação e, por tudo isso, energia viva e força criadora. Daí considerar, com Bergson (1988[1889], p. 116), uma psicologia grosseira aquela que nos apresenta a alma determinada seja por uma simpatia, por uma aversão ou pelo ódio: "esses sentimentos, contanto que tenham atingido uma profundidade suficiente, representam cada um a alma inteira, no sentido de que todo o conteúdo da alma se reflete em cada um deles".

Conceber a alma a partir de tal noção de determinação é conceber equivocamente a alma se determinando a si mesma. Reduzir o "eu" a um agregado de fatos de consciência, sensações, sentimentos e ideias, é conceber os estados de consciência a partir do nome que os exprime, é reter o que os estados têm de impessoal, de onde se segue sua justaposição indefinida e, assim, a mera obtenção de "um 'eu' fantasma, a 'sombra' do 'eu' que se projeta no espaço" (BERGSON, 1988[1889], p. 116). Se, pelo contrário, formos capazes de representar os estados de consciência naquilo que têm de próprio e inexprimível, torna-se desnecessário associar os estados de consciência para reconstituir a pessoa. A pessoa toda se encontra em cada um deles, e em um só deles. É neste fato, no qual um estado interno encontra manifestação exterior, que encontramos aquilo que podemos designar propriamente por ato livre. A manifestação exterior de um estado interno é o próprio ato livre, já que só o "eu" será o seu autor, ou seja, já que se trata da expressão do "eu" total. Daí Farias Brito (2003a[1914], p. 245) dizer que neste "eu" assim concebido, cada sentimento, cada emoção, cada concepção se confunde com o todo e forma uma só pessoa com ele: "quem não vê que aí [no associacionismo] se considera não o 'eu', mas simplesmente a sua projeção exterior no espaço, não a consciência, mas o seu fantasma objetivo?". Há vida em tudo o que se agita na alma, e mais que isso, cada sentimento, cada estado de consciência, cada paixão e emoção, concebidos per si, refletem a alma inteira, constituem o "eu" verdadeiro.

Um ato é tanto mais livre quanto mais a decisão livre é emanada pela alma inteira, isto é, "quanto mais a série dinâmica a que se religa tender para se identificar com o "eu' fundamental" (BERGSON, 1988[1889], p. 117). O mesmo diz Farias Brito (2003a[1914], p. 246), para quem:

O ato só é livre quando emana diretamente da alma, quando é obra do "eu", considerado este na sua significação real e concreta como organização dinâmica dos estados psicológicos sucessivos. Mas é necessário que estes estados psicológicos sejam considerados com a coloração particular que revestem numa pessoa determinada e que lhes vem, a cada um, do reflexo de todos os outros, de maneira que não é necessário associar muitos fatos de consciência para reconstituir a pessoa; ela está toda inteira em um só de entre eles, contanto que se saiba escolher. 
Mas é em função do fato de que o "eu" toca no mundo exterior pela superfície a razão pela qual não podemos dizer que a liberdade no homem é absoluta, como preconizara o espiritualismo e o dualismo. Nesse sentido, cumpre ressaltar o reconhecimento bergsoniano quanto ao fato de a consciência reconhecer duas dimensões distintas de vida: ao lado da dimensão inerente ao eu profundo, devemos lembrar sua constante ocupação com uma vida superficial. Daí a razão pela qual nem sempre é suficiente dizer que a primeira destas duas dimensões é o reino da qualidade e que a segunda e o reino da quantidade: mais que isso, referimo-nos a dois modos qualitativamente diferentes do "viver" da consciência. Se, por um lado, há uma consciência mais interna, de qualidade mais especificamente espontânea e dinâmica, há também uma consciência mais externa, de qualidade mais passiva e inerte. E, com efeito, é tal gradação de qualidades no interior da consciência o que nos permite afirmar que, em Bergson, também a liberdade admite graus.

Eis a razão pela qual Bergson não pode ser simplesmente considerado um "dualista". A liberdade, com efeito, admite graus:

[...] é preciso que todos os estados de consciência se misturem com seus congêneres, e como gotas de chuva à água de um lago. [Daí porque o "eu",] enquanto percepciona um espaço homogêneo, apresenta certa superfície, e nela poder-se-ão formar e flutuar vegetações independentes (BERGSON, 1988[1889], p. 116).

$\mathrm{O}$ associacionismo, apropriando-se do fato real de que grande parte de nossas ações cotidianas se executam a partir da solidificação de certas sensações, sentimentos e ideias em nossa memória - origem do hábito — defende a ideia de que nossas ações se reduzem aos movimentos gerados pelas impressões que vêm de fora, ainda que tais movimentos sejam conscientes ou inteligentes. Distinguindo os estados de consciência uns dos outros, o determinista desemboca invariavelmente em uma concepção mecânica do "eu", em que não há colorido a se distinguir nos estados internos, mas apenas impressões externas e mensuráveis, geradoras de respostas mecânicas no âmbito da consciência. Buscando estabelecer a representação simbólica como condição de apreensão do "eu" em sua especificidade, o determinista acaba por concebê-lo tão dividido quanto os sentimentos opostos que, por outra maneira, dividem o "eu". Confunde-se, destarte, uma divisão dinâmica e interna própria do "eu" com uma divisão mecânica da consciência. Este mecanismo, mostra Bergson, não se sustenta "contra o testemunho de uma consciência atenta, que nos apresenta o dinamismo interno como um fato" (BERGSON, 1988[1889], p. 117).

\section{Psicologia da LIBERdade}

Contra a posição determinista, é preciso reafirmar que a liberdade é um fato real, originada de atos que emanam de toda a nossa personalidade; é a liberdade, pois, o resultado de uma semelhança indefinível entre os atos livres e o conjunto inteiro de nossa personalidade: "em vão se alegará que cedemos então à influência todo-poderosa do nosso caráter" (BERGSON, 1988[1889], p. 120). 
Afinal, não há distinção entre nós mesmos e nosso caráter. A distinção da pessoa em duas partes, por um esforço de abstração, e com o intuito de distinguir o "eu" que pensa e sente em relação ao "eu" que age constitui um equívoco tão grave quanto o de conceber que modificamos livremente nosso caráter ou que nossa liberdade é suplantada com as aquisições assimiladas cotidianamente em nosso caráter. As aquisições cotidianas, que influem sobre nosso caráter, não se enxertam no nosso "eu", mas fundem-se com ele, e as mudanças que ocorrem em nosso caráter são totalmente nossas. Concordando em afirmar que é livre todo ato que emana apenas de nosso "eu", todo o ato no qual há a marca de nossa pessoa é igualmente livre, "porque só nosso 'eu' lhe reivindicará a paternidade" (BERGSON, 1988[1889], p. 120).

De pleno acordo com Stuart Mill (2005[1865]), e como Farias Brito, Bergson defende a ideia de que ter consciência do livre-arbítrio é ter a consciência de que é sempre possível escolher distintamente, o que remete à tarefa da consciência antes mesmo de se realizar uma ação. Com efeito, os defensores da liberdade em geral atribuem o poder da liberdade não ao próprio ato de escolher entre uma ou outra das ações contrárias possíveis, mas à capacidade que a consciência tem de sempre poder tomar uma das direções contrárias. Trata-se de uma atividade viva do "eu". A liberdade como atividade viva do "eu" é a razão porque se deve procurar a liberdade na qualidade da própria ação, e não na mera relação do ato com aquilo que não é ou com o que poderia ter sido. O estabelecimento da liberdade a partir destas relações é o que gera a obscuridade determinista, o que constitui a representação equívoca da deliberação a partir de uma oscilação entre duas opções a qual só se justifica no espaço. Em verdade, a liberdade diz respeito ao progresso dinâmico em que o "eu" e os próprios motivos confundem-se no devir, como verdadeiros seres vivos. Se a liberdade se afirma na duração deste "eu" que se sente livre e assim o declara é justamente porque a consciência pura "não se apercebe do tempo sob a forma de uma soma de unidades de duração; entregue a si própria, não tem nenhum meio, nenhuma razão até para medir o tempo" (BERGSON, 1988[1889], p. 127). Por outro lado, a consciência sente e declara sua liberdade certa de que é progresso, e não coisa; ora, mesmo que queiramos designar cada estado de consciência por meio da força da linguagem, eles não se deixam apreender por isso, pois mudam incessantemente; por conseguinte, suprimir cada um de seus momentos é empobrecê-lo em alguma impressão, é modificar e reduzir a qualidade que lhe é intrínseca. É, segundo Farias Brito, equívoco correspondente a "transportar para a natureza o princípio que teve sua origem em nó mesmos", de onde resulta que o "psíquico perde sua significação própria e de causalidade psíquica que fora tal como a verificamos em nós, transformando-se em causalidade mecânica" (BRITO, 2003a[1914], p. 254).

A hipótese de pré-visão dos atos futuros, um dos argumentos deterministas contra a existência real da liberdade, consiste na improcedente identificação do tempo que se reduz a um número - o mesmo ao qual recorrem astrônomos e físicos - com a duração real, aquela cuja quantidade é meramente aparente, pois na verdade é qualidade. Ora, a hipótese de previsão implica a redução gradativa do intervalo futuro, o que não é senão esvaziar ou empobrecer os estados de 
consciência que se sucedem, já que não se pode encurtar um instante sem que, ao mesmo tempo, se modifique a natureza dos fatos que a preenchem. Trata-se, pois, de uma hipótese a qual minimiza a significação do progresso que constitui a existência dos estados de consciência, reduzindo o fato psicológico a uma coisa que se pode representar de uma só vez. Por isso mesmo, dizer que certas causas internas produzem efeitos análogos é o mesmo que afirmar que a mesma causa se apresenta repetidamente na consciência. Ora, se a noção já definida de duração afirma apenas a heterogeneidade absoluta dos fatos psicológicos profundos, não há hipótese de que dois estados se assemelhem completamente, pois constituem dois momentos distintos da história, da duração. Eis porque não é possível o pensamento de que a mesma causa se apresente mais de uma vez na consciência:

Enquanto o objeto exterior não traz a marca do tempo decorrido e podendo assim o físico, apesar da diversidade dos momentos, encontrar-se perante condições elementares idênticas, a duração é coisa real para a consciência que dela conserva o vestígio, e não se pode aqui falar de condições idênticas, porque o mesmo momento não surge duas vezes (BERGSON, 1988[1889], p. 138).

[Se no âmbito das ciências naturais podemos falar legitimamente de uma] causalidade externa puramente matemática, [e] sem qualquer semelhança com relação da força psíquica ao ato que dela emana, [no âmbito da consciência podemos apenas falar de uma] causalidade interna, puramente dinâmica [e sem qualquer] analogia com a relação de dois fenômenos exteriores que se condicionam (BERGSON, 1988[1889], p. 138).

Ora, se os fenômenos externos são capazes de se reproduzir no espaço homogêneo, sendo assim redutíveis a leis gerais, os fatos psíquicos, por sua vez, apresentam-se à consciência apenas uma vez, sendo assim irrecuperáveis, senão pelo poder da memória.

Diante de tudo isso, pode-se enfim concluir que liberdade é um fato o qual diz respeito à relação indefinível que se estabelece entre o "eu" concreto com o ato que realiza. Se podemos analisar uma coisa, não podemos analisar um progresso; da mesma forma, se podemos decompor a extensão, não podemos decompor a duração. Transgredir tais princípios é o mesmo que transformar o progresso em coisa, a duração em extensão. A tentativa de dirimir o tempo concreto em decomposição implica desdobrar os momentos da duração real no espaço homogêneo: é substituir o "devir", o fato em permanente realização, pelo estático, pelo fato realizado; é congelar o "eu", é reduzir a espontaneidade à inércia e a liberdade à necessidade: 
Com efeito, definir-se-á o ato livre dizendo que este ato, uma vez realizado, poderia não o ter sido? Mas tal asserção - como a asserção contrária - implica a ideia de uma equivalência absoluta entre a duração concreta e o seu símbolo espacial: e desde que se admita essa equivalência, desemboca-se, pelo próprio desenvolvimento da fórmula que acabamos de denunciar, no mais inflexível determinismo (BERGSON, 1988[1889], p. 151).

Ora, é sob o equívoco da perspectiva determinista que se define o ato livre como aquele para o qual não há previsão possível, ainda que se conheçam antecipadamente todas as suas condições. Não obstante, mostra Bergson (1988[1889], p. 151), o pensamento de todas as condições como dadas “é, na duração concreta, colocar-se no próprio momento em que o ato se realiza", é ainda assim afirmar a liberdade. E é por isso que, equivocamente, acabamos reduzindo o tempo a um meio homogêneo e legitimamos a analogia entre a duração e seu símbolo quando admitimos a representação simbólica antecipada da matéria da duração psíquica. Por outro lado, definir o ato livre como todo aquele que não está determinado por sua causa, é estabelecer uma analogia improcedente entre a causalidade interna e a causalidade mecânica, de onde se segue a legitimação das ideias, também improcedentes, de que "os antecedentes psíquicos de um ato livre são suscetíveis de se reproduzir novamente, [de que] a liberdade se desenvolve numa duração cujos momentos se assemelham [e de que] o tempo é um meio homogêneo como o espaço" (BERGSON, 1988[1889], p. 151).

A liberdade, que é o fato mais claro de que temos notícia da consciência, só encontra dificuldades diante da tentativa de atribuir à duração as mesmas características que legitimamente atribuímos à extensão, de conceber a sucessão como simultaneidade, isto é, "de traduzir a ideia de liberdade para uma linguagem em que ela é evidentemente intraduzível” (BERGSON, 1998, p. 152).

\section{Considerações Finais:}

\section{A DURAÇÃO COMO OBJETO DA "CIÊNCIA DO ESPÍRITO"}

Ao conceber o "eu" em analogia com o compromisso numérico que se verifica na multiplicidade numérica, suprime-se a liberdade como um fato da consciência a partir da reconstituição de um estado psíquico pela adição de fatos psíquicos distintos e pela substituição do próprio "eu” por seu símbolo, por sua "sombra", pela superfície morta e estática. Ora, a duração, fora de nós, é uma multiplicidade qualitativa sem semelhança com o número, um desenvolvimento orgânico que não é quantidade crescente; é, enfim, uma heterogeneidade pura sem qualidades distintas: "em síntese, os momentos da duração interna não são exteriores uns aos outros" (BERGSON, 1988[1889], p. 156).

$\mathrm{Na}$ duração, fora de nós, só existe o presente, a simultaneidade, e se as coisas exteriores mudam, os seus momentos só se sucedem para uma consciência que, pelo poder da memória, as recorda. As simultaneidades anteriores não permanecem em si, e situar a duração no espaço constitui uma contradição flagrante, 
equivalente a conceber a sucessão pela simultaneidade. Na consciência, os estados se sucedem sem que, para tanto, se distingam, enquanto que, no espaço, as simultaneidades se distinguem sem que, para tanto, se sucedam. A incompreensão dessa dupla realidade, dessa dissociação, foi o que levou à negação da liberdade como o fato que mais essencialmente define a consciência: com efeito, pergunta-se "se o ato podia ou não ser previsto, dado o conjunto das suas condições; e quer se afirme, quer se negue, admite-se que este conjunto de condições se podia conceber como dado antecipadamente" (BERGSON, 1988[1889], p. 157-158). Trata-se, de uma maneira ou de outra, da tendência em conceber a "duração como uma coisa homogênea e as intensidades como grandeza", o que decerto é recair em determinismo. Da mesma forma, conceber o ato como determinado por suas condições, a partir da associação indevida entre causalidade interna e causalidade mecânica, ou invocar o princípio da conservação da energia, resultam no mesmo: identificação entre tempo e espaço, entre sucessão e simultaneidade. A intrusão da ideia de previsão no âmbito dos atos humanos não é senão a própria identidade que estabelecem entre fenômenos físicos e psíquicos, qualidade e quantidade, duração e extensão. Trata-se, enfim, de uma identificação indevida entre dois "eus" diferentes, cujo remédio é restituir a diferença entre duração e extensão, sucessão e simultaneidade, reconduzindo, assim, a liberdade ao domínio intemporal das coisas em si, já que o problema da liberdade, como consideram Bergson e Farias Brito, nasceu justamente desse mal-entendido que remete ao pensamento moderno, e segundo o qual o meio próprio do tempo e da duração é o espaço homogêneo.

O objeto de uma "ciência do espírito", portanto, é esse "eu" que se revela como princípio mesmo da ação, como atividade consciente e criação incessante. Nas palavras de Farias Brito (2003a[1914], p. 252), é a "ciência do espírito [o domínio do saber que tem por base o] poder indeterminado que não somente é capaz de agir por si mesmo, como, além disto, sempre que age eficazmente, produz alguma coisa de novo no mundo". Se ser livre é dominar-se, é exercer o governo sobre si mesmo e não sobre a natureza, o princípio da determinação universal perde toda significação no mundo dos fatos da consciência: "a verdadeira causalidade, a única pelo menos de que temos consciência, é a que impera em nós mesmos, e esta é psíquica, e só se nos apresenta como deliberação voluntária" (BRITO, 2003a[1914], p. 252).

\section{Nota}

1 A aproximação entre Farias Brito e Henri Bergson constitui um primeiro momento da pesquisa aqui apresentada. Para os próximos estágios, estão previstas análises aprofundadas de outras obras de Bergson, tais como Matéria e Memória (1999[1896]) e A Evolução Criadora (2005[1907]), sem as quais esta pesquisa não pode ser considerada efetivamente empreendida. 


\section{REFERÊNCIAS}

BERGSON, H. Ensaios sobre os dados imediatos do conhecimento (1889). Tradução de João da Silva Gama. Lisboa: Edições 70, 1988.

BERGSON, H. Matéria e Memória: ensaio sobre a relação do corpo com o espírito (1896). 2. ed. Trad. Paulo Neves. São Paulo: Martins Fontes, 1999.

BERGSON, H. A Evolução Criadora (1907). Trad. Bento Prado Neto. São Paulo: Martins Fontes, 2005.

BRITO, R. F. Finalidade do Mundo: Estudos de Filosofia e Teleologia Naturalista (1905). Rio de Janeiro: INL, 1957.

BRITO, R. F. O Mundo interior: ensaio sobre os dados gerais da Filosofia do Espírito (1914). Lisboa: Imprensa Nacional-Casa da Moeda, $2003 \mathrm{a}$.

BRITO, R. F. Ensaio sobre o Conhecimento (1914). Lisboa: Imprensa NacionalCasa da Moeda, 2003b.

BRITO, R. F. A verdade como regra das ações: ensaio de filosofia moral como introdução ao estudo do direito (1905). Brasília: Senado Federal, 2005.

MILL, J. S. An examination of Sir William Hamilton's philosophy and of the principal philosophical questions discussed in his writings (1865). Ann Arbor, Michigan: University of Michigan Library, 2005.

Recebido em: novembro de 2009

Aceito em: fevereiro de 2011 